\title{
Corrigendum: Cutter-disc consumption during earth pressure balance tunneling in mixed strata
}

\section{Khalid Elbaz}

PhD Researcher, State Key Laboratory of Ocean Engineering, School of Naval Architecture, Ocean, and Civil Engineering, Shanghai Jiao Tong University, Shanghai, P. R. China; Collaborative Innovation Center for Advanced Ship and Deep-Sea Exploration (CISSE), Shanghai, P. R. China

\section{Shui-Long Shen}

Professor, State Key Laboratory of Ocean Engineering, School of Naval Architecture, Ocean, and Civil Engineering, Shanghai Jiao Tong University, Shanghai, P. R. China; Collaborative Innovation Center for Advanced Ship and Deep-Sea Exploration (CISSE), Shanghai, P. R. China

\section{Wen-Chieh Cheng}

Professor, Institute of Tunnel and Underground Structure Engineering, School of Civil Engineering, Xi'an University of Architecture and University, Beilin, Xi'an, P. R. China

\section{Arul Arulrajah}

Professor, Department of Civil and Construction Engineering, Swinburne University of Technology, Victoria, Australia

The authors would like to present their sincere acknowledgements for the discusser's valuable comments on the original article (Elbaz et al., 2018a, 2018b), which the authors have found useful to enhance the technical soundness of the article. The authors regret that errors have been identified in two sections of the text and in Figures 13 and 14, corrections for which are detailed below.

The location of the sinkhole is not within zone 6 , but within zone 1 , as mentioned in an earlier publication by the corresponding author (Cui et al., 2015). The cause of the formation of this sinkhole is most likely owing to instability of the excavation face. During the initial tunnel construction stage (100 rings), the pressure applied to the foam to ensure excavation face stability was still under adjustment. Unfortunately, the foam spilled out from the ground surface while erecting the initial 100 rings, thereby triggering formation of the sinkhole.

The last three paragraphs in section 4.6 ('Challenges and problems faced') have been replaced by the paragraph below.

In December 2013, an incident involving a ground surface collapse occurred while erecting ring 44 within zone 1 of weathered limestone. The cause of the formation of this sinkhole is most likely owing to instability of the excavation face. During the initial tunnel construction stage (100 rings), the pressure applied to the foam to ensure excavation face stability was still under adjustment. Unfortunately, the foam spilled out from the ground surface while erecting the initial 100 rings, thereby triggering the $5 \mathrm{~m}$ long, $2 \mathrm{~m}$ deep sinkhole. No casualties were recorded for this incident. This sinkhole was then filled with mortar, while the karst caverns nearby were treated using the binary slurry. The replacement of excavation tools, machine maintenance and additional ground investigation resulted in a significant delay of 5 months.

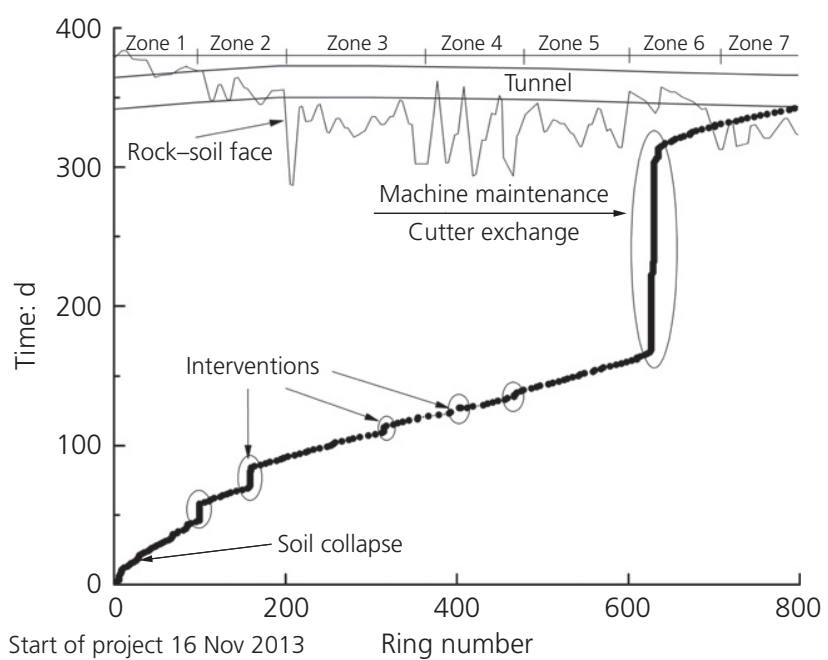

Figure 13. Relationship between the construction schedule and the tunnelling distance for the Ma-Lian section

The last point in section 5 ('Conclusions') has been replaced by the paragraph below.

(d) The pressure applied to the foam failed to maintain the excavation face stability most likely because of its adjustment during the initial tunnel construction stage (within 100 rings), thereby triggering a $5 \mathrm{~m}$ long, $2 \mathrm{~m}$ deep sinkhole. This sinkhole and nearby karst caverns were treated immediately following this incident to prevent further development.

Figure 13 has been revised to reflect the updated information.

Figure 14 has been removed from the article.

The authors sincerely apologise for the errors and any inconvenience caused. 


\section{REFERENCES}

Cui QL, Wu HN, Shen SL, Xu YS and Ye GL (2015) Chinese karst geology and measures to prevent geohazards during shield tunnelling in karst region with caves. Natural Hazards 77(1): 129-152.

Elbaz K, Shen SL, Cheng WC and Arulrajah A (2018a) Cutter-disc consumption during earth pressure balance tunnelling in mixed strata. Proceedings of the Institution of Civil
Engineers - Geotechnical Engineering 171(4): 363-376, https://doi.org/10.1680/jgeen.17.00117.

Elbaz K, Shen SL, Cheng WC, Arulrajah A and Shirlaw JN (2018b)

Discussion: Cutter-disc consumption during earth pressure balance tunnelling in mixed strata. Proceedings of the Institution of Civil Engineers - Geotechnical Engineering 171(6): 559-561, https://doi.org/10.1680/jgeen.18.00129. 